\title{
EFFECTS OF POWER FREQUENCY ALTERNATING MAGNETIC FIELDS ON REPRODUCTION AND PRE-NATAL DEVELOPMENT OF MICE
}

\author{
Yasuyuki OHNISHI ${ }^{1}$, Fumio MIZUNO ${ }^{1}$, Tetsuya $\mathrm{SATO}^{1}$, Mitsuru YASUI ${ }^{2}$, \\ Takehiko KIKUCHI ${ }^{2}$ and Masahiro OGAWA ${ }^{2}$ \\ ${ }^{1}$ Mitsubishi Chemical Safety Institute, \\ 14 Sunayama, Hasaki-machi, Kashima-gun, Ibaraki 314-0255, Japan \\ ${ }^{2}$ Engineering Development Center, Tokyo Electric Power Co., Ltd., \\ 4-1 Egasaki-cho, Tsurumi-ku, Yokohama 230-0002, Japan
}

(Received September 12, 2001; Accepted March 15, 2002)

\begin{abstract}
Three groups of ICR male and female mice were exposed to 50-Hz, sinusoidal, alternating, horizontal magnetic fields of $0.0 \mathrm{mT}$ (sham), $0.5 \mathrm{mT}$ and $5.0 \mathrm{mT}$ (rms) for 9 and 2 weeks prior to mating for males and females, respectively, through fertilization and until cesarean sectioning. Fetuses were collected by cesarean section on the 18th day of gestation. Approximately half were randomly selected for skeletal examination and the remainder used for visceral examination. No significant differences were found between the field- and the sham-exposed groups in pre-, post- and total implantation losses; number of live fetuses; sex ratio; live fetal weight; number of externally abnormal fetuses; and numbers of fetuses with skeletal and visceral anomalies. These results suggest that exposure to power-frequency magnetic fields has no major effects on reproduction and development in mice, and do not support the association of EMF exposure with adverse reproductive effects suggested by epidemiology.
\end{abstract}

KEY WORDS: Reproduction, Mouse, Magnetic field, Power-frequency, Teratology, Reproductive performance

\section{INTRODUCTION}

Debate on the adverse effect on health of a nonionizing electromagnetic field (EMF) was triggered by epidemiology in 1970s in the U.S. The debate concentrated on the extremely low frequency (ELF, $<300 \mathrm{~Hz}$ ) region, and especially power frequency, because of social impact. In the ELF region, electric and magnetic fields can be separated, and the former faded away from debate in the early stage owing to its poor environmental transmission.

A large number of studies was performed on the bioeffects of the ELF magnetic field, for the most part related to cancer and reproduction. We undertook our experiment under such circumstances.

Some epidemiological studies have reported potential effects on human reproduction from exposure to power-frequency $(50-$ or $60-\mathrm{Hz})$ electromagnetic fields, including both parental occupational exposure to electric and magnetic fields and domestic and occupational use of electric appliances by pregnant women (Meyers et al., 1989). Since Wertheimer and Leeper, 1988, reported a significant increase in spontaneous abortion during the season in which electric blankets, waterbeds and ceiling heaters were used, several additional reports have been published concerning abortion incidence. Some of them (Sanjose et al., 1991; Juutilainen et al., 1993) supported the positive association, but others (Klauenberg, 1991; Hatch, 1992) did not. Some other reproductive outcomes were studied in epidemiology, including birth weight, congenital anomalies, sex ratio, etc. Wertheimer and Leeper, 1986, reported a slightly elevated risk of low birth weight. Bracken et al., 1995, supported them using dosimeters, but Savitz and Ananth, 1994, did not. As for congenital anomalies, Olsham et al., 1991, reported an increased risk of atrial septal defect in the offspring of electricians, electric and electronic workers. However, 
Dlugosz et al., 1992, and Robert, 1993, reported slightly decreased risks of some types of malformations in the exposed groups.

Reproduction tests using animals exposed to power-frequency, sinusoidal magnetic fields are less numerous, and the results generally did not show an adverse effect. Kowalczuk et al., 1994, observed a significant increase in litter size and a decrease in frequency of external anomaly, and no significant effect on pre-implantation survival in CD1 mice exposed to a $50-\mathrm{Hz}, 20 \mathrm{mT}$ magnetic field. In another study, they observed no significant effect on pregnancy rate, preand post-implantation survivals in a dominant lethal test using CD1 male mice exposed to a field of $10 \mathrm{mT}$. Martin, 1992, reported no effect of $60-\mathrm{Hz}, 3 \mu \mathrm{T}$ (PTP, Peak-to-peak) sinusoidal and DC-biased, sinusoidal magnetic field exposure on chick embryos in the most sensitive development period, the first $48 \mathrm{hr}$ after fertilization. Huuskonen et al., 1993, however, reported significant increases in both numbers of implantation and live fetuses and in incidence of fetuses with minor skeletal anomalies in Wistar rats exposed continuously to a $50-\mathrm{Hz}, 35.6 \mu \mathrm{T}(\mathrm{PTP})(13 \mu \mathrm{Trms})$, sinusoidal magnetic field. These authors (Juutilainen et al., 1997; Huuskonen et al., 1998) performed another reproduction study using $\mathrm{CBA} / \mathrm{Ca}$ mice exposed to magnetic fields, including the same field as in the previous study, and observed no significant effects on any endpoints, although insignificant increases in incidences of skeletal variations were reproduced.

Given both the importance of the question that power-frequency magnetic fields could influence reproduction and pre-natal development and the limited number of experiments available, we completed a reproduction and teratology test using ICR mice exposed to strong magnetic fields.

\section{MATERIALS AND METHODS}

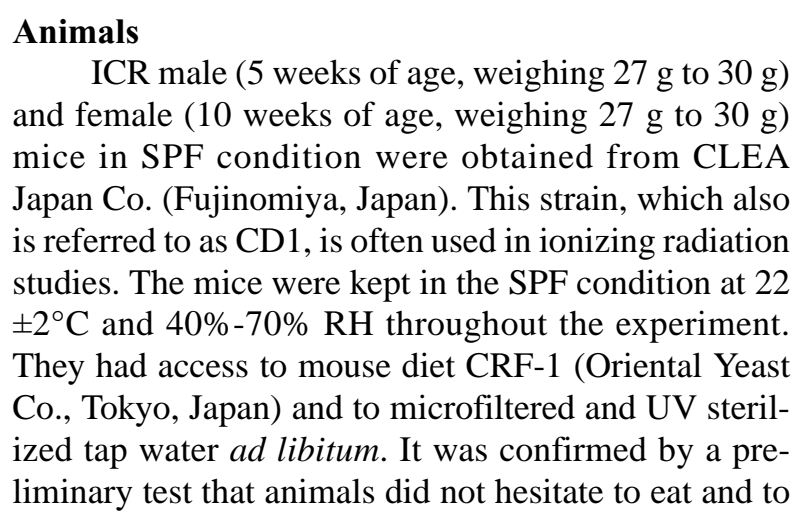

drink from the stainless steelware in the field. The lighting schedule was lights-on from 06:00-18:00.

\section{Magnetic field}

The International Radiation Protection Association (IRPA), 1990, recommended $0.5 \mathrm{mT}$ as the occupational continuous exposure limit in its interim guideline. We adopted this as the lower level of exposure, and we used a field intensity 10 times higher (5.0 $\mathrm{mT})$. Animals were exposed to the fields using an exposure facility with structure and performance reported elsewhere in detail (Yasui and Otaka, 1993). Performance is shown in Table 1. The magnetic field is automatically switched off when a person enters the exposure room to avoid exposing workers to the field. Average exposure time was $23.0 \mathrm{hr} /$ day for males and $22.7 \mathrm{hr} /$ day for females.

Although a higher flux density is preferable in order to enhance the exposure effect, $5.0 \mathrm{mT}$ is almost the technically attainable limit for a large-scale animal exposure system. Magnetic field from an electric blanket was estimated as $1 \mu \mathrm{T}$ (IEC 61000-2-7) and those in occupational and residential environments as 4$0.2 \mu \mathrm{T}$. $5.0 \mathrm{mT}$ was regarded as strong enough compared with actual human exposure.

\section{Treatment}

The procedure (Fig.1) was based on OECD guidelines 414, 1981, and 415, 1983, for chemical testing. Thirty-five male mice were exposed to a sham $(0.0$ $\mathrm{mT}), 0.5 \mathrm{mT}$ or $5.0 \mathrm{mT}(\mathrm{rms})$ magnetic field for 9 weeks, long enough to cover at least one complete spermatogenic cycle. In order to detect a subtle effect, a large-scale experiment was preferable, but there was a limit imposed by the exposure system capacity. At 15 weeks of age, each male was mated with a female 13 weeks of age exposed to a sham $(0.0 \mathrm{mT}), 0.5 \mathrm{mT}$ or

Table 1. Performance of exposure facility. Details of the facility are described elsewhere, together with the building for maintenance of SPF condition.

\begin{tabular}{ll}
\hline Frequency & $50 \mathrm{~Hz}$ \\
Flux density & Sham $(0.1-1 \mu \mathrm{T}), 0.5 \mathrm{mT}$ and $5.0 \mathrm{mT}$ \\
Exposure space & $2.64 \mathrm{~W} \times 0.18 \mathrm{H} \times 0.56 \mathrm{D} \times 2 \times 3$ sets \\
Flux uniformity & $\pm 10 \%$ \\
Flux direction & Horizontal \\
Acoustic noise & Lower than $60 \mathrm{~dB}(\mathrm{~A})$ \\
Stability of current & Within $\pm 0.4 \%$ \\
Distortion of wave form & Lower than $3 \%$ \\
\hline
\end{tabular}


Effects of magnetic fields on reproduction in mice.

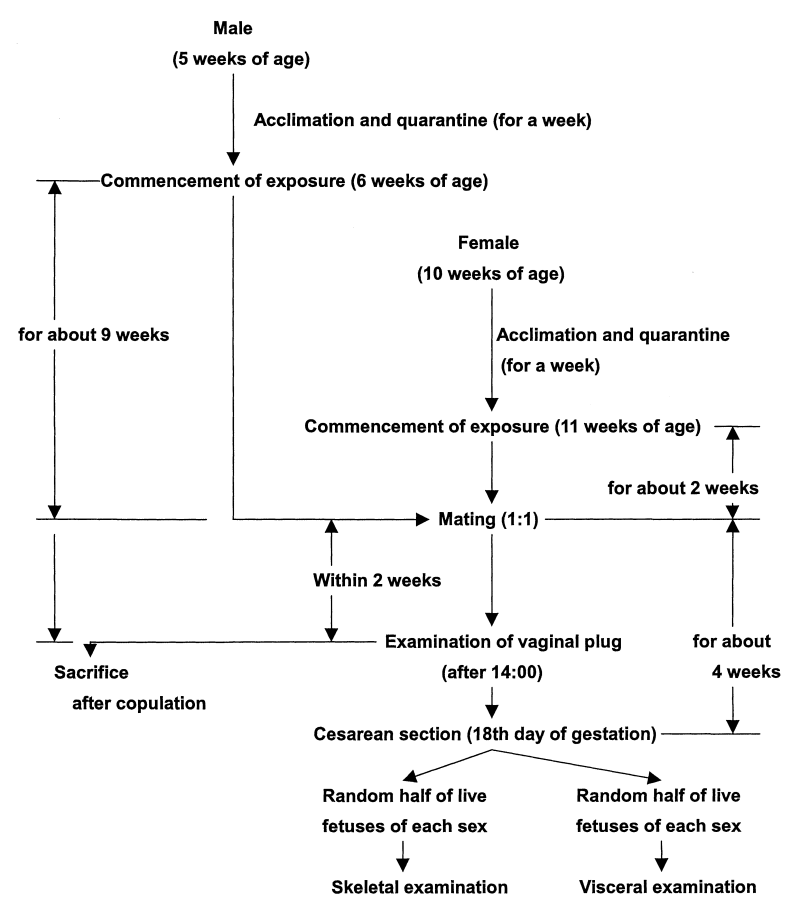

Fig. 1. Flow diagram of experiment. Mice of both sexes were exposed to the fields from 9 and 2 weeks prior to mating for male and female, respectively, through fertilization and until cesarean sectioning. Mating was monogamous and ended at the day when a vaginal plug was observed or after 2 weeks.

$5.0 \mathrm{mT}(\mathrm{rms})$ field of the same strength for 2 weeks, i.e. at least two complete estrous cycles. The animals were checked for vaginal plug after 14:00 in order to avoid switching off the fields during the most sensitive teratogenic period ( $6 \mathrm{hr}$ to $8 \mathrm{hr}$ after fertilization), which occurs at about 04:00 (Nomura, 1984). When a vaginal plug was observed, the male was removed. Pairs that had no copulation were kept without exchanging mates for 2 weeks. Non-pregnant females were also exposed to the fields and then assessed in the same manner as pregnant ones. Animals of both sexes were monitored for health throughout the experiment by measurement of body weight and food consumption and by performance of a standardized clinical observation procedure.

\section{Examination}

Exposure continued until the 18th day of gestation, when fetuses were removed by cesarean section under ether anesthesia. The numbers of corpora lutea, implants, early (before completion of the placenta) and late fetal deaths, and live fetuses of both sexes were recorded. Fetal sex was determined by anogenital distance. Live fetuses were weighed and examined for external malformations. A "dwarf" was defined as a fetus with a weight less than $75 \%$ of the mean of its litter weight for each sex. Non-pregnant females were also examined by hysterotomy for uterine contents at the end of the procedure. Approximately half of the live fetuses of each sex were selected randomly for skeletal examination and the remainder used for visceral examination. Skeletal examination was performed microscopically after Alizarine red S staining, and visceral examination was performed by Wilson's method (Wilson, 1965). Malformation was distinguished from variation according to Federal Register 56: 63798, 1991.

\section{Statistical analysis}

Metric data were tested for homogeneity of variance by Bartlett's method followed by ANOVA or Kruscal-Wallis test (Kruscal and Wallis, 1952) depending on the results of Bartlett's test (Bartlett, 1937). Numeration data were tested by Fisher's exact method. The tests were performed between the real- and the sham-exposed groups, because a dose-response relationship had not yet been established between the flux density and any bioeffects. Fetal data were analyzed on the basis of litter mean values.

\section{RESULTS}

In the clinical observation of the parents under exposure, two significant decreases in mean body weight were detected in the $0.5 \mathrm{mT}$ group versus the control for males at the 21st and 28th day of exposure, but these decreases were of a transient nature (data not shown).

No significant $(\mathrm{p}<0.05)$ effects of exposure were detected by external, skeletal and visceral examinations of fetuses, by examination of uterine contents in dams and in reproductive performance. Although insignificant, the results are shown below in detail.

\section{External anomaly}

Table 2 summarizes the results of external examination of fetuses. Percent of external anomalies $(1.9 \%$, $1.7 \%$, and $1.6 \%$ for sham, $0.5 \mathrm{mT}$, and $5.0 \mathrm{mT}$ groups, respectively) seems to indicate a slightly decreasing trend with increasing field strength as in Kowalczuk et al., 1994. Although incidence of open eyelid appears to increase in the exposed groups, the differences were not significant. 
Y. OHNISHI et al.

Table 2. Observations on external anomalies. Club foot is expected to recover with growth. Exencephaly and cleft palate were considered to be fatal.

\begin{tabular}{|c|c|c|c|c|c|}
\hline \multirow[t]{2}{*}{ Dependent variable } & \multicolumn{3}{|c|}{ Number of animals $(\%)$} & \multirow{2}{*}{$\begin{array}{c}\text { Historical } \\
\text { Control (S.D.) }\end{array}$} & \multirow[t]{2}{*}{ Reference* } \\
\hline & Sham & $0.5 \mathrm{mT}$ & $5.0 \mathrm{mT}$ & & \\
\hline No. of dams & 28 & 32 & 34 & 40 & \\
\hline No. of abnormal fetuses/ & $7 / 368$ & $7 / 412$ & $7 / 447$ & $1 / 261$ & \\
\hline Total live fetuses & $(1.9 \%)$ & $(1.7 \%)$ & $(1.6 \%)$ & $(0.3 \%)$ & \\
\hline No. of dams with abnormal fetuses & $7(1.7 \%)$ & $5(1.6 \%)$ & $7(1.5 \%)$ & $2.5 \%$ & $0-0.58 \%$ \\
\hline Open eyelid & $1(0.3 \%)$ & $3(0.7 \%)$ & $3(0.7 \%) \dagger$ & $0.3(1.4)$ & 0.09 \\
\hline Club foot & $3(0.8 \%)$ & $4(1.0 \%)$ & $3(0.7 \%)$ & 0 & $0.09-0.18$ \\
\hline Kink tail & $1(0.3 \%)$ & $0(0 \%)$ & $0(0 \%)$ & 0 & NA \\
\hline Cleft palate & $1(0.3 \%)$ & $0(0 \%)$ & $1(0.2 \%)$ & 0 & $0.13-0.35$ \\
\hline Exencephaly & $0(0 \%)$ & $0(0 \%)$ & $1(0.2 \%) \dagger$ & $0.3(1.4)$ & 0.06 \\
\hline Polydactyly & $1(0.3 \%)$ & $0(0 \%)$ & $0(0 \%)$ & 0 & NA \\
\hline Dwarf & $3(0.8 \%)$ & $1(0.2 \%)$ & $2(0.4 \%)$ & NA & NA \\
\hline
\end{tabular}

$\dagger:$ A fetus with open eyelid and exencephaly.

*: Nakatsuka et al., 1997, in Crj: CD-1 and Slc: ICR.

NA: Not available.

\section{Skeletal anomaly}

Table 3 summarizes the results of skeletal examination of the fetuses. No increase was observed in the incidence of skeletal malformations. Some increases in the incidence of variations, i.e., splitting of the ossification center in the cervical vertebral arches, cervical ribs, accessory sternebra, and 14th ribs (extra thoracic rib), were observed in the $0.5 \mathrm{mT}$ group, but no trend with field strength was apparent. Table 4 shows degree of ossification.

\section{Anomaly of internal organs}

Table 5 summarizes the results of visceral examination of the fetuses. Two fetuses, from two dams, with localized ventricular septal defect were found in the $5.0 \mathrm{mT}$ group. Abnormal origin of the right subclavian artery, a rare malformation in this laboratory, was seen in the $5.0 \mathrm{mT}$ group. As for variation, incidences of supernumerary coronary orifice were 2,4 , and 5 in the sham, $0.5 \mathrm{mT}$, and $5.0 \mathrm{mT}$ groups, respectively.

\section{Dead embryo and implantation loss}

Table 6 summarizes the results of examining of uterine contents in dams. Spontaneous abortion was a main issue of epidemiological studies on EMF. Dead embryos and implantation loss are related to it. Preimplantation loss was $8.1 \%$ in the $5.0 \mathrm{mT}$ group versus $4.8 \%$ in the sham group, and the number of dead embryos in the early stage was 0.8 in the $0.5 \mathrm{mT}$ group versus 0.4 in the sham group. Although statistically insignificant, both are 5\% marginal. Compared with historical control data, $13.5 \%$, the former can be regarded as within the fluctuation. Numbers of dead embryos in the late stage of gestation were almost equal between the exposure levels.

Lack of a change in the sex ratio is consistent with the results of Kowalczuk et al., 1994, and inconsistent with the result of Huuskonen et al., 1993, who reported increases in total implants and live fetuses in the exposed groups.

Total implants and total live fetuses were consistent with the reference data. Insignificant increases in number of total dead embryos and total implantation losses were observed in the exposed groups, which seem to compensate for the insignificant increase in total implants to yield equal numbers of total live fetuses.

\section{DISCUSSION}

Spontaneous abortion was the main concern of the epidemiological studies on EMF in human reproductive outcomes, and the elevated risks were found in most of the epidemiological studies, although the lower limits of the $95 \%$ confidence intervals were below 1 . The results of the present study did not support elevated risk. The results on dead embryos in Table 6 alone did not support a causal relation of $50-\mathrm{Hz}$ magnetic field and spontaneous abortions. 
Effects of magnetic fields on reproduction in mice.

Table 3. Results of skeletal examinations of fetuses. Variation is a minor anomaly, mostly expected to recover with growth, and never affects viability. Some litters had many fetuses with skeletal anomalies; for example, accessory sternebra. Skeletal development was anticipated to be affected by EMF even if sinusoidal, but the possible effect is not large enough to be detectable.

\begin{tabular}{|c|c|c|c|c|}
\hline & Sham & $0.5 \mathrm{mT}$ & $5.0 \mathrm{mT}$ & Reference \\
\hline No. of dams & 28 & 32 & 34 & \\
\hline No. of fetuses examined & 190 & 214 & 234 & \\
\hline \multicolumn{5}{|l|}{ No. of fetuses and litter mean $\%$ with } \\
\hline Bifurcation of the cervical vertebral arches & $30(14.9 \%)$ & $28(13.0 \%)$ & $44(17.9 \%)$ & 0.80 \\
\hline Splitting of ossification center of the cervical vertebral arches & $10(5.2 \%)$ & $18(8.2 \%)$ & $16(7.3 \%)$ & $0.27-0.53$ \\
\hline Fusion of the cervical vertebral arches $\dagger$ & $0(0 \%)$ & $0(0 \%)$ & $1(0.5 \%)$ & 0.23 \\
\hline Cervical ribs & $25(12.4 \%)$ & $38(18.6 \%)$ & $33(13.4 \%)$ & NA \\
\hline Fusion of the sternebrae $\uparrow$ & $1(0.5 \%)$ & $0(0 \%)$ & $0(0 \%)$ & $0.26-1.23$ \\
\hline Accessory sternera & $16(8.5 \%)$ & $33(15.3 \%)$ & $12(4.7 \%)$ & NA \\
\hline Splitting of the sternebrae & $1(0.5 \%)$ & $0(0 \%)$ & $0(0 \%)$ & NA \\
\hline Asymmetry of the sternebrae & $1(0.4 \%)$ & $0(0 \%)$ & $2(0.8 \%)$ & NA \\
\hline Splitting of ossification centers of the 14 th ribs & $1(0.5 \%)$ & $0(0 \%)$ & $1(0.3 \%)$ & NA \\
\hline 14 th ribs & $37(20.5 \%)$ & $58(27.0 \%)$ & $50(20.8 \%)$ & NA \\
\hline Lumbarization of the sacral vertebrae & $2(1.2 \%)$ & $0(0 \%)$ & $0(0 \%)$ & NA \\
\hline Sacralization of the lumbar vertebrae & $5(2.6 \%)$ & $2(0.9 \%)$ & $1(0.4 \%)$ & 0.08 \\
\hline Total & $100(52.3 \%)$ & $124(57.8 \%)$ & $116(47.4 \%)$ & \\
\hline
\end{tabular}

$\dagger$ : Malformation, No mark: Variation, * is affixed if significantly different from sham.

Reference: Nakatsuka et al., 1998. In Crj: CD-1 and Slc: ICR.

Table 4. Degree of ossification. An ossified bone is observed as a stained spot with Alizarine red S in the skeleton of the fetus under an optical microscope.

\begin{tabular}{|c|c|c|c|c|c|}
\hline \multicolumn{3}{|l|}{ 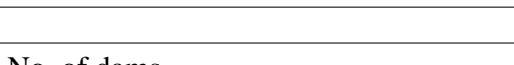 } & Sham & $0.5 \mathrm{mT}$ & $5.0 \mathrm{mT}$ \\
\hline \multirow{2}{*}{\multicolumn{3}{|c|}{$\begin{array}{l}\text { No. of dams } \\
\text { No of fetuses examined }\end{array}$}} & 28 & 32 & 34 \\
\hline & & & 190 & 214 & 234 \\
\hline \multirow[t]{2}{*}{ Vertebrae } & & $6.90(0.32)$ & $6.98(0.07)$ & $6.71(1.17)$ \\
\hline & \multicolumn{2}{|l|}{ Caudal centra } & $10.38(1.36)$ & $10.71(0.98)$ & $9.99(1.73)$ \\
\hline \multicolumn{3}{|l|}{ Hyoid } & $1.00(0.00)$ & $0.98(0.09)$ & $1.00(0.00)$ \\
\hline \multirow[t]{2}{*}{ Incisor } & \multicolumn{2}{|l|}{ Upper } & 0 & 0 & 0 \\
\hline & Lower & & $2.00(0.00)$ & $2.00(0.00)$ & $1.99(0.06)$ \\
\hline \multicolumn{3}{|l|}{ Sternebra } & $5.99(0.03)$ & $6.00(0.00)$ & $6.00(0.00)$ \\
\hline \multirow{2}{*}{\multicolumn{2}{|c|}{ Metacarpus }} & Left & $4.00(0.00)$ & $4.00(0.00)$ & $3.98(0.09)$ \\
\hline & & Right & $4.00(0.00)$ & $4.00(0.00)$ & $3.98(0.09)$ \\
\hline \multirow[t]{6}{*}{ Manus } & \multirow[t]{2}{*}{ Proximal } & Left & $3.99(0.05)$ & $4.00(0.00)$ & $3.88(0.48)$ \\
\hline & & Right & $3.98(0.05)$ & $4.00(0.00)$ & $3.88(0.48)$ \\
\hline & \multirow[t]{2}{*}{ Medial } & Left & $2.70(0.47)$ & $2.91(0.44)$ & $2.66(0.72)$ \\
\hline & & Right & $2.76(0.48)$ & $2.94(0.38)$ & $2.73(0.70)$ \\
\hline & \multirow[t]{2}{*}{ Distal } & Left & $4.93(0.26)$ & $5.00(0.00)$ & $4.88(0.51)$ \\
\hline & & Right & $4.92(0.26)$ & $5.00(0.00)$ & $4.88(0.51)$ \\
\hline \multirow{2}{*}{\multicolumn{2}{|c|}{ Metatarsus }} & Left & $4.99(0.03)$ & $4.99(0.04)$ & $4.98(0.10)$ \\
\hline & & Right & $4.99(0.03)$ & $4.99(0.04)$ & $4.98(0.10)$ \\
\hline \multirow[t]{6}{*}{ Pes } & \multirow[t]{2}{*}{ Proximal } & Left & $4.95(0.20)$ & $4.99(0.04)$ & $4.82(0.68)$ \\
\hline & & Right & $4.95(0.20)$ & $4.99(0.04)$ & $4.82(0.68)$ \\
\hline & \multirow[t]{2}{*}{ Medial } & Left & $1.79(1.04)$ & $2.13(0.97)$ & $2.01(1.04)$ \\
\hline & & Right & $1.76(1.05)$ & $2.19(0.95)$ & $2.03(1.06)$ \\
\hline & \multirow[t]{2}{*}{ Distal } & Left & $5.00(0.00)$ & $5.00(0.00)$ & $4.85(0.66)$ \\
\hline & & Right & $5.00(0.00)$ & $5.00(0.00)$ & $4.85(0.66)$ \\
\hline
\end{tabular}

Litter mean of number of ossified bones (standard deviation).

$*$ is affixed if significantly different from sham. 


\section{Y. OHNISHI et al.}

Table 5. Observations of internal organs of fetuses. Left umbilical artery is a very slight variation. The malformations are fatal.

\begin{tabular}{|c|c|c|c|c|}
\hline Dependent variable & Sham & $0.5 \mathrm{mT}$ & $5.0 \mathrm{mT}$ & Reference \\
\hline No. of dams & 28 & 32 & 34 & NA \\
\hline No. of fetuses examined & 178 & 198 & 213 & NA \\
\hline \multicolumn{5}{|l|}{ No. of fetuses (litter mean \% with) } \\
\hline Abnormal origin, r't subclavian artery $\dagger$ & $0(0 \%)$ & $0(0 \%)$ & $1(0.5 \%)$ & NA \\
\hline Deformity of the heart $\dagger$ & $1(0.6 \%)$ & $0(0 \%)$ & $0(0 \%)$ & NA \\
\hline Localized ventricular septal defect $\dagger$ & $0(0 \%)$ & $0(0 \%)$ & $2(1.1 \%)$ & NA \\
\hline Supernumerary coronary orifice & $2(0.8 \%)$ & $4(2.0 \%)$ & $5(2.0 \%)$ & 0.11 \\
\hline Congenital diaphragmatic hernia $\uparrow$ & $0(0 \%)$ & $0(0 \%)$ & $1(0.4 \%)$ & NA \\
\hline Left umbilical artery & $35(18.8 \%)$ & $26(13.1 \%)$ & $35(15.3 \%)$ & NA \\
\hline Total & $38(19.4 \%)$ & $30(15.1 \%)$ & $43(18.9 \%)$ & \\
\hline
\end{tabular}

$\dagger$ : Malformation; No mark: variation.

Reference: Nakatsuka et al., 1997.

NA: Not available.

Table 6. Observations on uterine contents. Early and late in the dead embryo were distinguished by existence of a placenta; pre-implantation loss is the difference between numbers of corpora lutea and total implants.

\begin{tabular}{|c|c|c|c|c|c|}
\hline \multirow[t]{2}{*}{ Dependent variable } & \multicolumn{3}{|c|}{ Group mean (standard deviation) } & \multirow{2}{*}{$\begin{array}{c}\text { Historical } \\
\text { control }\end{array}$} & \multirow[t]{2}{*}{ Reference } \\
\hline & Sham & $0.5 \mathrm{mT}$ & $5.0 \mathrm{mT}$ & & \\
\hline Number of dams & 28 & 32 & 34 & 40 & \\
\hline Corpora lutea & $14.6(2.06)$ & $14.7(1.88)$ & $15.1(2.09)$ & $15.4(2.8)$ & 13.9-17.4 \\
\hline Total implants & $13.8(2.10)$ & $14.0(1.94)$ & $14.0(2.92)$ & $13.2(2.7)$ & $12.8-14.9$ \\
\hline \multicolumn{6}{|l|}{ Dead embryos } \\
\hline Early & $0.4(0.63)$ & $0.8(1.22)$ & $0.7(0.84)$ & $0.5(0.6)$ & NA \\
\hline Late & $0.2(0.50)$ & $0.3(0.60)$ & $0.2(0.48)$ & $0.3(0.6)$ & NA \\
\hline Total & $0.6(0.69)$ & $1.1(1.49)$ & $0.9(0.81)$ & $0.8(0.9)$ & $8.0-10.4$ \\
\hline \multicolumn{6}{|l|}{ Implantation loss (\%) } \\
\hline Pre- & $4.8(4.95)$ & $4.7(5.73)$ & $8.1(13.8)$ & $13.5(15.7)$ & NA \\
\hline Post- & $4.5(5.13)$ & $7.8(10.3)$ & $6.8(8.01)$ & $5.7(7.1)$ & NA \\
\hline Total & $9.3(6.08)$ & $12.0(12.4)$ & $14.2(15.2)$ & $18.7(15.3)$ & $12.8-14.7$ \\
\hline \multicolumn{6}{|l|}{ Live fetuses } \\
\hline Male & $6.2(2.11)$ & $6.1(2.37)$ & $6.1(2.26)$ & $6.4(2.0)$ & NA \\
\hline Female & $6.9(1.96)$ & $6.8(2.25)$ & $7.1(2.52)$ & $6.1(2.2)$ & NA \\
\hline Total & $13.1(2.24)$ & $12.9(2.35)$ & $13.1(3.13)$ & $12.5(2.8)$ & $11.7-13.1$ \\
\hline \multicolumn{6}{|l|}{ Live fetal weight (g) } \\
\hline Male & $1.54(0.10)$ & $1.53(0.08)$ & $1.52(0.12)$ & $1.41(0.11)$ & $1.35-1.48$ \\
\hline Female & $1.47(0.10)$ & $1.47(0.07)$ & $1.46(0.11)$ & $1.37(0.09)$ & $1.32-1.43$ \\
\hline Sex ratio $(M / F)$ & 174/194 (0.90) & $194 / 217(0.90)$ & $206 / 241(0.85)$ & $254 / 245(1.04)$ & NA \\
\hline
\end{tabular}

Reference: Nakatsuka et al., 1997.

NA: Not available. 
Effects of magnetic fields on reproduction in mice.

Table 7. Measures of reproductive performance. Unlike the human male, it was considered that male mice might be affected by EMF through contact of the testes with the cage wall possibly charged in the fields. The data shows the fields did not affect male mice.

\begin{tabular}{lcccc}
\hline Dependent variable & Sham & $0.5 \mathrm{mT}$ & $5.0 \mathrm{mT}$ & Historical control \\
\hline Pre-coital days & 2.5 & 3.0 & 2.4 & $2.3(1.3)$ \\
Coital rate $(\%)$ & 94 & 97 & 100 & $100^{*}$ \\
Pregnancy rate $(\%)$ & 91 & 94 & 97 & 93 \\
\hline
\end{tabular}

*: $90.5 \%$ by the breeder's background data, Jcl Information $97-1030$.

Jansson et al., 1993, suggested in their epidemiological study that an increase in spontaneous abortion owing to exposure might cause a decrease in the number of anomalies, but the number of dead embryos in Table 6 is not consistent with this suggestion.

Some epidemiological studies were directed to low birth weight and growth retardation. Results on live fetal weight in Table 6 are far from showing significant differences between the exposure levels. Numbers of dwarfs in Table 2 were 3, 1 , and 2 (from a dam) in the sham, $0.5 \mathrm{mT}$, and $5.0 \mathrm{mT}$ groups, respectively, which did not support a possible adverse effect of the field on fetal development.

As for congenital anomaly, the results of the epidemiological studies were inconsistent, and increase in risk was small if any.

Insignificant increases were observed in (1) number of dead embryos in the early stage of gestation in the $0.5 \mathrm{mT}$ group, (2) pre-implantation loss in the 5.0 $\mathrm{mT}$ group, (3) incidence of open eyelid in the exposed groups, and (4) incidence of cervical ribs and accessory sternebra in the $0.5 \mathrm{mT}$ group, but they were not consistent with the results of Kowalczuk et al., 1994.

\section{CONCLUSION}

No effects of 50-Hz, up to $5.0 \mathrm{mT}$ magnetic fields were detected on reproduction in mice. This supports none of the associations between the field and human reproductive outcome suggested by epidemiological studies. Additional studies are needed to evaluate the possible effects with enhanced detection power.

\section{ACKNOWLEDGMENT}

The authors thank Profs. Hiraku Takebe, Takeshi Shiga, Masamichi Kato and Eisuke Masada, EMF Quality Assurance Committee, and Prof. Taisei Nomura, Osaka Univ., for helpful advice and discussion.

\section{REFERENCES}

Bartlett, M.S. (1937): Properties of sufficiency and statistical tests. Proc. Roy. Soc., A160, 268-282.

Bracken, M.B., Belanger, K., Hellenbrand, K., Dlugosz, L., Holford, T.R., McSharry, J.E., Addesso, K. and Leaderer, B. (1995): Exposure to electromagnetic fields during pregnancy with emphasis on electrically heated beds: Association with birth weight and intrauterine growth retardation. Epidemiology, 6, 263-270.

Dlugosz, L., Vena, J., Byers, T., Sever, L., Bracken, M. and Marshall, E. (1992): Congenital defects and electric bed heating in New York State: A register-based case-control study. Am. J. Epidemiol., 135, 1000-1011.

Hatch, M. (1992): Epidemiology of electric and magnetic field exposures in the power frequency range and reproductive outcome. Paediatr. Pernat. Epidemiol., 6, 198-214.

Huuskonen, H., Juutilainen, J. and Komulainen, H. (1993): Effects of low-frequency magnetic fields on fetal development in rats. Bioelectromagnetics, 14, 205-213.

Huuskonen, H., Juutilainen, J., Julkunen, A., MakiPaakkanen, J. and Komulainen, H. (1998): Effects of low-frequency magnetic fields on fetal development in CBA/Ca mice. Bioelectromagnetics, 19, 477-485.

IRPA (1990): Interim guidelines on limits of exposure to $50 / 60 \mathrm{~Hz}$ electric and magnetic fields. Health Phys., 58, 113-122.

Jansson, E., Dlugosz, L., Bracken, M., Vena, J., Byers, T., Sever, L. and Marshall, E. (1993): Re: "Congenital defects and electric bed heating in New York State: A register-based case-control study. (letter and reply)". Am. J. Epidemiol., 137, 585587.

Juutilainen, J., Matilainen, P., Saarikoski, S., Laara, E. and Suonio, S. (1993): Early pregnancy loss and 
exposure to $50-\mathrm{Hz}$ magnetic fields. Bioelectromagnetics, 14, 229-236.

Juutilainen, J., Huuskonen, H. and Komulainen, H. (1997): Increased resorptions in CBA mice exposed to low frequency magnetic fields: An attempt to replicate earlier observations. Bioelectromagnetics, 18, 410-417.

Klauenberg, B.J. (1991): Re: "Fetal loss associated with two seasonal sources of electromagnetic field exposure". Am. J. Epidemiol., 134, 913916.

Kowalczuk, C.I., Robbins, L., Thomas, J.M., Butland, B.K. and Saunders, R.D. (1994): Effects of prenatal exposure to $50 \mathrm{~Hz}$ magnetic fields on development in mice. I. Implantation rate and fetal development. Bioelectromagnetics, 15, 349-361.

Kruscal, W.H. and Wallis, W.A. (1952): Use of ranks in one-criterion variance analysis. J. Am. Statist. Assoc., 47, 583-621.

Martin, A.H. (1992): Development of chicken embryos following exposure to $60-\mathrm{Hz}$ magnetic fields with differing wave forms. Bioelectromagnetics, 13, 223-230.

Meyers, R.E., Aldrich, T.E. and Easterly, C.E. (1989): Effects of noise and electromagnetic fields on reproductive outcomes. Environ. Health Perspect., 81, 193-200.

Nakatsuka, T., Horimoto, M., Ito, M., Matsubara, Y., Akaike, M. and Ariyuki, F. (1997): Japan pharmaceutical manufacturers association (JPMA) survey on background control data of development and reproductive toxicity studies in rats, rabbits and mice. Cong. Anom., 37, 47-138.

Nomura, T. (1984): High sensitivity of fertilized eggs to radiation and chemicals in mice: Comparison with that of germ cells and embryos at organogenesis. Cong. Anom., 24, 329-337.

OECD Guideline for testing of chemicals. 414 (1981) and 415 (1983).

Olsham, A.F., Teschke, K. and Baird, P.A. (1991): Paternal occupation and congenital anomalies in offspring. Am. J. Ind. Med., 20, 447-475.

Robert, E. (1993): Birth defects and high voltage power lines: An exploratory study based on registry data. Reprod. Toxicol., 7, 283-287.

Sanjose, S., Roman, E. and Beral, V. (1991): Low birth weight and preterm delivery, Scotland, 1981-84: effect of parents' occupation. Lancet, 338, 428431

Savitz, D.A. and Ananth, C.V. (1994): Residential magnetic fields, wire codes, and pregnancy outcome. Bioelectromagnetics, 15, 271-273.

US EPA (1991): Federal Register 56: 63798.

Wertheimer, N. and Leeper, E. (1986): Possible effects of electric blankets and heated waterbeds on fetal development. Bioelectromagnetics, 7, 1322.

Wertheimer, N. and Leeper, E. (1988): Fetal loss associated with two seasonal sources of electromagnetic field exposure. Am. J. Epidemiol., 129, 220-224.

Wilson, J.G. (1965): Methods for administering agents and detecting malformations in experimental animals. In Teratology. Principles and Techniques. (Wilson, J.G. and Warkany, J., eds.), pp.262-277, The University of Chicago Press, Chicago and London.

Yasui, M. and Otaka, Y. (1993): Facility for chronic exposure of rats to ELF magnetic fields. Bioelectromagnetics, 14, 535-544. 